\title{
Current Therapeutic Strategies for Adipose Tissue Defects/Repair Using Engineered Biomaterials and Biomolecule Formulations
}

\author{
Christopher M. Mahoney ${ }^{1}$, Cayla Imbarlina'2, Cecelia C. Yates ${ }^{3,4,5}$ and Kacey G. Marra ${ }^{1,5,6 *}$ \\ ${ }^{1}$ Department of Bioengineering, University of Pittsburgh, Pittsburgh, PA, United States, ${ }^{2}$ Department of Biology, Carlow \\ University, Pittsburgh, PA, United States, ${ }^{3}$ Department of Pathology, University of Pittsburgh, Pittsburgh, PA, United States, \\ ${ }^{4}$ Department of Health Promotion and Development, School of Nursing, University of Pittsburgh, Pittsburgh, PA, \\ United States, ${ }^{5}$ McGowan Institute for Regenerative Medicine, Pittsburgh, PA, United States, ${ }^{6}$ Department of Plastic \\ Surgery, University of Pittsburgh, Pittsburgh, PA, United States
}

OPEN ACCESS

Edited by:

Ryan James Gilbert,

Rensselaer Polytechnic Institute,

United States

Reviewed by:

Yong Li,

University of Texas Health Science Center at Houston, United States

Keekyoung Kim,

University of British Columbia,

Canada

${ }^{*}$ Correspondence:

Kacey G. Marra

marrak@upmc.edu

Specialty section:

This article was submitted to

Integrative and Regenerative

Pharmacology,

a section of the journal

Frontiers in Pharmacology

Received: 15 December 2017

Accepted: 27 April 2018

Published: 17 May 2018

Citation:

Mahoney CM, Imbarlina C, Yates CC and Marra KG (2018) Current

Therapeutic Strategies for Adipose

Tissue Defects/Repair Using

Engineered Biomaterials

and Biomolecule Formulations.

Front. Pharmacol. 9:507.

doi: 10.3389/fphar.2018.00507
Tissue engineered scaffolds for adipose restoration/repair has significantly evolved in recent years. Patients requiring soft tissue reconstruction, caused by defects or pathology, require biomaterials that will restore void volume with new functional tissue. The gold standard of autologous fat grafting (AFG) is not a reliable option. This review focuses on the latest therapeutic strategies for the treatment of adipose tissue defects using biomolecule formulations and delivery, and specifically engineered biomaterials. Additionally, the clinical need for reliable off-the-shelf therapies, animal models, and challenges facing current technologies are discussed.

Keywords: microspheres, adipose-derived stem cells, soft tissue defects, adipose tissue restoration, adipogenic factors

\section{INTRODUCTION}

Adipose tissue is distributed throughout the body and is categorized by location such as subcutaneous (arm, abdominal, and gluteal), intraabdominal (omental, retroperitoneal, and visceral) and other sites (retroorbital, periarticular regions, bone marrow, intramuscular, and pericardial). Adipose tissue plays an essential role in the protection of underlying structures, providing insulation, contributing function, and imparting a normal human appearance. This appearance, and even function, can be compromised by disease, trauma, tumor resection, or congenital defects of the subcutaneous adipose tissue. These pathologies and defects of the adipose tissue remain a reconstructive challenge for plastic surgeons and clinicians. According to the American Society of Plastic Surgeons, the most common reconstructive procedures are breast construction, burn care, cleft lip/palate repair, tumor removal, and treatment from dog bites (ASPS, 2017). In particular, from 2009 to 2014, the Agency for Healthcare Research and Quality reported an increase in breast reconstruction after mastectomy by 62 percent (Miller et al., 2017).

Two major reconstruction options for breast adipose tissue deficits in the clinic include implant or flap surgery using the patient's own skin, fat, and/or muscle. Currently, flap surgeries are not without morbidity. Patients receiving autologous reconstruction are at high risk for specific complications including wound infection, flap/prosthesis failure, and reoperation. Other general complications of major surgery such as deep vein thrombosis, blood transfusions, pneumonia, and 
pulmonary embolism can lead to prolonged length of stay in the hospital (Tachi and Yamada, 2005; Agha et al., 2013). Patients undergoing implant-based reconstruction may encounter complications such as rupture, migration, discontent, implant exposure/extrusion, rippling, and deformation/distortion (Rocco et al., 2016). With the volume of complications to consider using these invasive procedures, clinicians and patients are looking for less or minimally invasive options.

In effort to reduce the risk of complications, clinicians have increased the use of a widely used procedure in plastic surgery known as autologous fat grafting (AFG). Assuming the patient has adipose tissue to spare, AFG harvests the patient's own fat, typically from the abdomen or thighs, via liposuction and deposits the tissue into the defect site with syringe injections. AFG is usually minimally invasive and carries several advantages in comparison to implant- or flap-based soft tissue reconstruction. With minimal scarring from the defect site and no foreign body reaction, the patient recovery time is less than $48 \mathrm{~h}$. However, while the general outcomes for these procedures are positive in the short-term, the long-term results can be unpredictable due to post-graft resorption rates reaching as high as 90\% (Hong et al., 2010; Monfort and Izeta, 2012). Another minimally invasive technique used for contour defects incorporates in vitro cultured adipocytes via injection (Kim et al., 2011). Unfortunately, this procedure's efficacy is limited to eyelid wrinkles, deep nasolabial folds, depressed scars, and less projected forehead (Gir et al., 2012b; Monfort and Izeta, 2012).

The field of adipose tissue engineering evolved to address the clinical need discussed earlier. The following sections describe how current therapies insufficiently restore body contour. This review focuses on the wide range of biomaterials for resolving adipose tissue defects and the most current cutting edge therapeutic strategies, specifically encapsulated biomolecules. This comprehensive overview guides the rationale for the need of a reliable off-the-shelf biomaterial that will mostly likely contain a scaffold-encapsulation therapy combination to restore and repair the adipose defect site.

\section{BIOACTIVE MOLECULES FOR ADIPOSE TISSUE REPAIR}

An increasingly widespread trend for adipose restoration has been to incorporate additional biomolecules or biological factors with scaffold material to facilitate new adipose tissue formation, thus creating composite biomaterials. Multi-component materials are becoming a common approach in recent years producing interesting results. Basic fibroblast growth factor-2 (FGF-2) (Kawaguchi et al., 1998; Kimura et al., 2003; Vashi et al., 2006; Zhang et al., 2016), fibroblast growth factor-1 (FGF-1) (Moya et al., 2010), dexamethasone (Rubin et al., 2009; Sun et al., 2013; Fan et al., 2015; Jia et al., 2015; Kelmendi-Doko et al., 2017), adipose-derived stem cells (ASCs) (Wang et al., 2013; Cheung et al., 2014; Brown et al., 2015), pioglitazone (Yazawa et al., 2015), insulin (Masuda et al., 2004; Rubin et al., 2009; Hong et al., 2010), and insulin-like growth factor-1 (IGF-1)
(Masuda et al., 2004) are among several additive components that have been evaluated in vitro/in vivo. Several methods of encapsulation have been used to localize the delivery of the therapeutic agents. Table 1 contains a comprehensive list of therapeutic agents, encapsulation strategies used, and the expected biological responses from their use. The effects of these therapeutic agents on preadipocyte differentiation and adipose tissue have been described further in illustration (Figure 1). FGF-2 is a member of fibroblast growth factors and most widely used angiogenic factor to stimulate blood vessel infiltration and subsequent de novo adipogenesis ( $\mathrm{Lu}$ et al., 2014; Jiang et al., 2015; Zhang et al., 2016). Insulin binds to IGF-1 receptors to mimic most of the biological effects of IGF-1 ( $\mathrm{Lu}$ et al., 2014). IGF-1 and insulin activates phosphorylation of cAMP response element binding protein (CREB) in preadipocytes to induce differentiation while also regulating triglyceride synthesis through sterol regulatory element-binding protein-1c (SREBP1c) (Widberg et al., 2009; Lu et al., 2014). Vascular endothelial growth factor (VEGF) is a major regulator of vasculogenesis and angiogenesis, serving as a mitogen for vascular endothelial cells (EC) along with several other roles (Chung et al., 2012). Pioglitazone hydrochloride (P-zone) promotes peroxisome proliferator activated receptor- $\gamma$ (PPAR- $\gamma$ ) mRNA expression in preadipocytes, a critical step in adipogenesis, as well as increases mRNA levels of insulin responsive glucose transporter (GLUT4) (Lu et al., 2014; Yazawa et al., 2015). It is believed that FGF-1 increases expression of PPAR- $\gamma$ and members of the CCAAT enhancer binding protein (C/EBP) family of transcription factors to prime preadipocytes for proliferation and differentiation (Hutley et al., 2004; Widberg et al., 2009). Dexamethasone (Dex) targets activating transcription factor 4 (ATF4) to initiate adipocyte differentiation in preadipocytes (Widberg et al., 2009). Direct comparisons of these additives in the appropriate animal model as well as their feasibility for commercial production are imperative for developing a clinically relevant adipogenic biomaterial.

\section{AUTOLOGOUS ADIPOSE GRAFT IMPLANTATION AND ENHANCEMENT STRATEGIES}

Depending on the clinical indication, the standard of care for adipose tissue repair and regeneration may vary as well as their outcomes. For cases such as breast reconstruction, lipoatrophy, scleroderma, face rejuvenation, gluteal augmentation, craniomaxilla-facial deformities, etc., the gold standard of care is an AFG (Monfort and Izeta, 2012). AFG is a safe, resourceful, and minimally invasive option which allows the patient's body to provide its own non-immunogenic, compatible biomaterial (Hong et al., 2010; Gir et al., 2012a; Agha et al., 2013). The liposuction technique and fat processing of AFG has significantly evolved over the past century with the advancement of technologies used to perform the procedure and examination of studies to optimize graft survival. As seen in Figure 2, many plastic surgeons have adopted the "lipo-structure technique" or Coleman technique for the microinjection of fat particles to 
TABLE 1 | Therapeutic agents for adipose tissue defects.

\begin{tabular}{|c|c|c|c|}
\hline Drugs/biomolecules & Methods of delivery & Cellular response & Reference \\
\hline Dexamethasone & Double-emulsion/solvent extraction & $\begin{array}{l}\text { Down-regulate expression of } \\
\text { preadipocyte factor- } 1 \text { (pref-1) }\end{array}$ & $\begin{array}{l}\text { Rubin et al., 2009; Sun et al., 2013; } \\
\text { Fan et al., 2015; Jia et al., 2015; } \\
\text { Kelmendi-Doko et al., } 2017\end{array}$ \\
\hline Insulin & $\begin{array}{l}\text { Double-emulsion/solvent extraction; } \\
\text { photocured to gelatin }\end{array}$ & $\begin{array}{l}\text { stimulates glucose uptake, lipogenesis, } \\
\text { and inhibits lipolysis through IGF-1 }\end{array}$ & $\begin{array}{l}\text { Masuda et al., 2004; Rubin et al., } 2009 \\
\text { Tan et al., 2010; Kim et al., } 2016\end{array}$ \\
\hline $\begin{array}{l}\text { Insulin-like growth factor-1 } \\
\text { (IGF-1) }\end{array}$ & Photocured to gelatin & $\begin{array}{l}\text { Activates AKT and MAPK signaling } \\
\text { pathways }\end{array}$ & Masuda et al., 2004; Kim et al., 2016 \\
\hline $\begin{array}{l}\text { Basic fibroblast growth factor-2 } \\
\text { (FGF-2) }\end{array}$ & $\begin{array}{l}\text { Mixed heparinized protein; photocured } \\
\text { to gelatin; hydrogel supplement; double } \\
\text { emulsion }\end{array}$ & upregulates mitotic genes & $\begin{array}{l}\text { Kawaguchi et al., 1998; Kimura et al., } \\
\text { 2003; Masuda et al., 2004; Zhang } \\
\text { et al., } 2016\end{array}$ \\
\hline $\begin{array}{l}\text { Pioglitazone hydrochloride } \\
\text { (P-zone) }\end{array}$ & Saline gel mixture & $\begin{array}{l}\text { Ligand for PPAR- } \gamma \text {; increase GLUT4 } \\
\text { expression }\end{array}$ & Yazawa et al., 2015 \\
\hline $\begin{array}{l}\text { Vascular endothelial growth } \\
\text { factor (VEGF) }\end{array}$ & Double-emulsion/solvent extraction & $\begin{array}{l}\text { Mitogen for vascular EC; increase EC } \\
\text { migration, regulate microvascular } \\
\text { permeability and vasodilation }\end{array}$ & $\begin{array}{l}\text { Zhu et al., 2010; Chung et al., 2012; } \\
\text { Topcu et al., } 2012\end{array}$ \\
\hline $\begin{array}{l}\text { Fibroblast growth factor-1 } \\
\text { (FGF-1) }\end{array}$ & Heparin incubation & increase PPAR- $\gamma$ expression & Widberg et al., 2009; Moya et al., 2010 \\
\hline
\end{tabular}

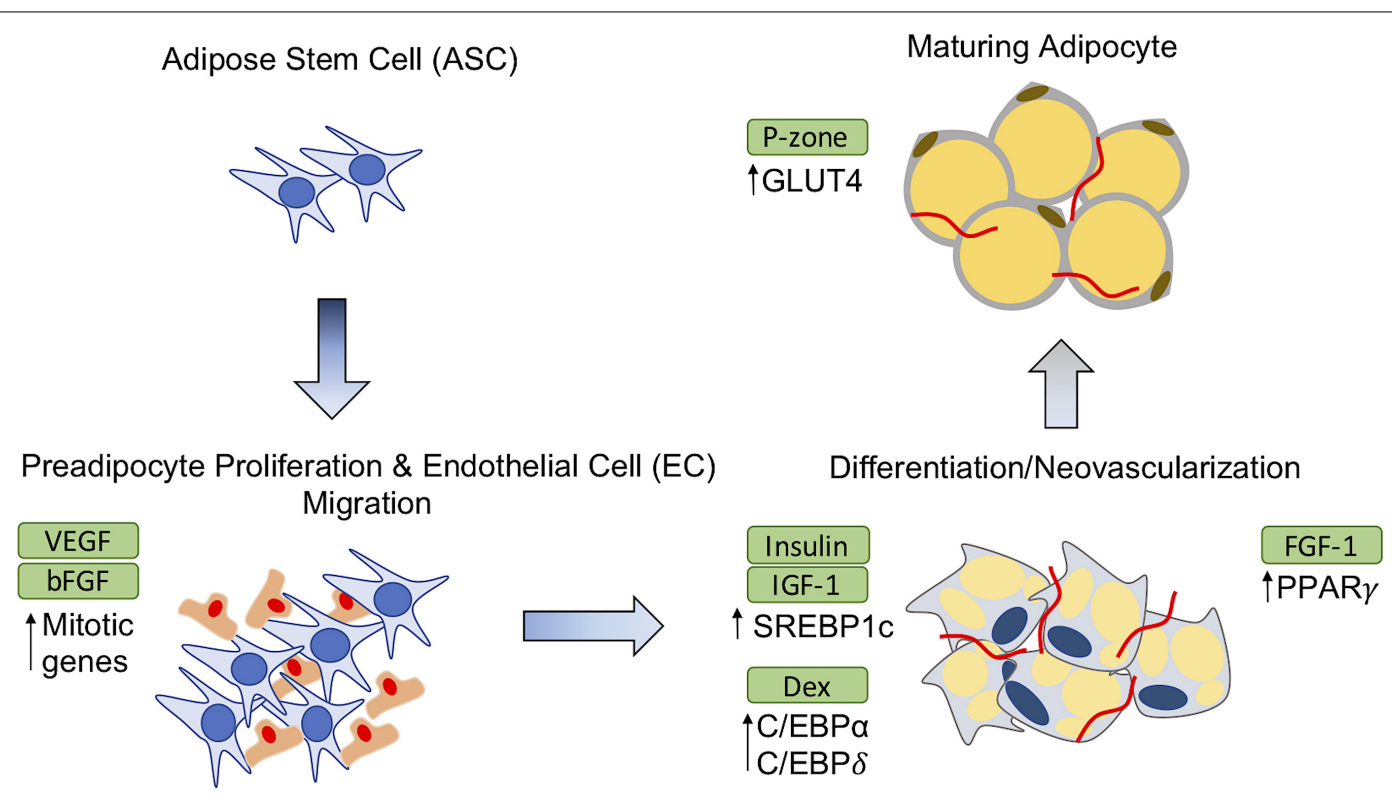

FIGURE 1 | Effects of therapeutic agents on adipose-derived stem cell (ASC) differentiation. The addition of exogenous agents in adipose restoration therapies affect precursor adipocytes and maturing adipocytes in different ways to induce adipogenesis or vascularization. GLUT4, Glucose transporter; C/EBP, CCAT enhanced binding protein; SREBP1c, sterol regulatory element-binding protein-1c; FGF-2, Fibroblast growth factor-2; FGF-1, Fibroblast growth factor-1; P-zone, Pioglitazone hydrochloride; EC, endothelial cell; PPAR, peroxisome proliferator activated receptor; VEGF, vascular endothelial growth factor; Dex, Dexamethasone; IGF-1, insulin-like growth factor-1.

minimize fat graft loss. Using a Coleman microcannula, light negative pressure is created by drawing the plunger of a 10$\mathrm{ml}$ syringe connected to a 3-mm cannula when introduced in the subcutaneous cavity per a small incision. The cannula is moved through the adipose section manually, loosening the tissue, and collecting the fat into the syringe. For processing, the collected fat tissue is transferred to $10 \mathrm{~mL}$ tubes for centrifugation to separate into four layers: (a) oily fraction; (b) aqueous fraction; (c) a cell pellet; and (d) the purified fat flanked by the oily and aqueous fractions (Simonacci et al., 2016). Centrifugation at $3000 \mathrm{rpm}$ for $3 \mathrm{~min}$ is the standard for separation of fractions, but there is literature that suggests slower speeds may reduce adipocyte disruption (Gir et al., 2012a). Following centrifugation, the middle layer of viable adipocytes is transferred to $1 \mathrm{cc}$ syringes. Successful graft implantation is executed using blunt tip cannulas to create tunnels at insertion, with small aliquots of fat injected at different depths of the defect. Multiple passes are utilized to 


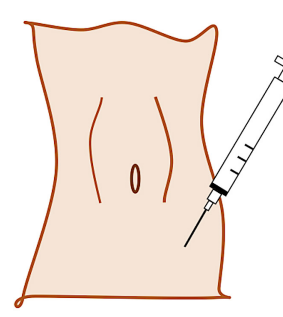

Harvest: 3-mm cannula moved through adipose to loosen and collect fat

\section{LIPO-STRUCTURE TECHNIQUE}

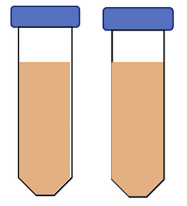

Processing:

Collected fat transferred to tubes for centrifugation

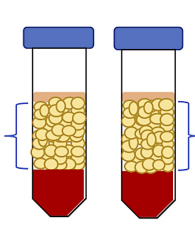

Separation: Centrifuge setting at $3000 \mathrm{rpm}$ for 3 min is standard to separate fractions

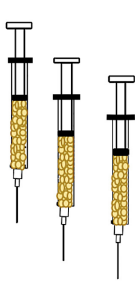

Isolation: Middle layer of viable adipocytes is transferred to $1 \mathrm{cc}$ syringes

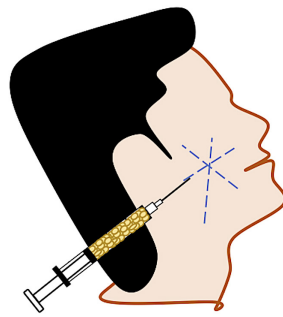

Implantation:

Small aliquots of fat injected at different depths of defect

FIGURE 2 | Lipo-structure technique for autologous fat grafting (AFG). Lipo-structure technique is a frequently used procedure for filling an adipose defect. The technique is performed in the operating room by plastic surgeons as the gold standard.

reach throughout the site of interest. Due to the unpredictable character of AFG, the majority of clinicians overcorrect volume deficiencies from 20 to 30\% (Kaufman et al., 2007; Tabit et al., 2012).

While AFG is a widely utilizes treatment, there can be complications. Experienced physicians using the preferred technique may encounter unsatisfactory results such as fat necrosis, calcification, oil cyst formation, and hypertrophic scarring (Gir et al., 2012a; Philips et al., 2014; Nahabedian, 2015; Simonacci et al., 2016). Largo et al. (2014) reviewed several publications following the results of over 1400 patients. The studies containing volume retention data documented values varying from 55 to $82 \%$. Other studies have reported resorption rates from 30 to $70 \%$ (Kaufman et al., 2007; Kurita et al., 2008). There are several mechanisms that contribute to the variability of outcomes from AFG. The trauma caused by liposuction can lead to apoptosis of adipocytes and cyst formation. The different degrees of blood supply and fluctuations in oxygen delivery of the recipient wound may range from adequate revascularization to insufficient revascularization and ischemia, apoptosis, and dedifferentiation of essential adipocytes. An accepted principle of fat grafting is that adipocytes within $2 \mathrm{~mm}$ of an arterial blood supply have greatest chance of survival (Tabit et al., 2012; Bourne et al., 2016).

New therapies which include both biomolecules and cells are now being studied to increase viability within AFG and consistently enhance retention. For example, Phipps et. al proposed the use of M2 macrophages to improve fat graft retention via proangiogenic factors such as VEGF and basic fibroblast growth factor-2 (FGF-2) (Phipps et al., 2015). Additionally, M2 macrophages provide matrix metalloproteinases required for endothelial sprouting and vascular network formation. Investigators injected fat grafts $\left(150 \mathrm{~mm}^{3}\right)$ with saline or M2 macrophages under the scalps of C57BL/6 mice. After 3 months, M2 supplemented grafts resulted in significantly higher mean volumes and exhibited an increase in vascular density compared to controls. Hong et al. (2010) explored the strategy of using supplemented transfer medium containing insulin and FGF-2 to enhance the viability of autologous fat grafts transplanted between the muscle and subcutaneous tissue of New Zealand white rabbits. Fat grafts were immersed for $5 \mathrm{~min}$ in either supplemented transfer medium or saline before transplantation. The insulin-supplemented fat grafts retained approximately $40 \%$ of original weight while fat grafts soaked in saline only retained $\sim 15 \%$ of original weight after 12 months. Additionally, groups treated with insulin and fibroblast growth factor showed larger number of mature adipocytes, and reduced cyst formation compared to the group treated with saline, at both 6 and 12 months after autologous fat transplantation.

Researchers have utilized biomaterials to encapsulate growth factors and pharmaceuticals aiming to develop clinically relevant tissue engineering therapies (Rubin et al., 2009; Chung et al., 2012; Topcu et al., 2012; Zhang et al., 2016). VEGF was encapsulated in calcium alginate microspheres to create a controlled release system and was evaluated in a Wistar rat model receiving fat grafts (Topcu et al., 2012). Rats in groups 1 and 2 received microspheres (MS) containing $2 \mu \mathrm{g} / 0.1 \mathrm{~mL}$ VEGF subdermally 21 days prior to fat grafting and mixed within fat graft, respectively. After 90 days, the fat graft control group lost over $50 \%$ of weight while groups receiving VEGF calcium alginate MS showed an increase in weight over $25 \%$. Microvascular density results were also significantly higher in the VEGF microsphere pre-injection group and VEGF MS mixed with fat graft group. VEGF has also been encapsulated in poly(lactic-co-glycolic) (PLGA) MS as a potential therapy for transferred human lipoaspirate (Chung et al., 2012). Human lipoaspirate with and without PLGA VEGF MS were injected into the flanks of athymic mice and evaluated up to 6 weeks for vascularization and tissue survival. Significantly higher mean masses and volumes in the VEGF-loaded microsphere group were seen at 6 weeks. Additionally, there was IHC staining qualitatively displayed increased vascularization in the VEGF MS group at 6 weeks compared to 3 weeks results.

Rubin et al. utilized PLGA MS to encapsulate two adipogenic factors, dexamethasone (Dex) and insulin, as a method to 
stimulate adipogenesis in ASCs. Results showed that ASCs treated with dexamethasone and insulin microspheres contained a significantly higher number of adipocytes compared to control groups (Rubin et al., 2009). More recently, Kelmendi-Doko et al. (2014) utilized this same microsphere delivery system with encapsulated adipogenic factors to increase retention of transplanted adipose tissue. Dex and insulin were loaded into PLGA MS and mixed at various doses with human fat grafts to be injected subcutaneously into the dorsal aspect of athymic mice. After 5 weeks, volume analysis showed increased graft retention with use of Dex-loaded PLGA MS. Blood vessel density was also increased with the use of the adipogenic encapsulated MS. Kelmendi-Doko et al. (2017) extended the investigation of Dex MS in a double-walled (DW) formulation mixed into human fat grafts. Control human fat grafts explanted from athymic mice after 6 months demonstrated significant volume loss (i.e. $\sim 90 \%$ ) while groups containing the DW Dex MS resulted in a mean volume loss of $\sim 33 \%$, thus demonstrating the beneficial effects of a slow, controlled release delivery system.

In another study, Masuda et al. (2004) proposed the co-release of insulin with additional encapsulated drugs from styrenated, gelatin-based microspheres (SGM). Insulin, IGF-1, and FGF-2 were encapsulated to develop a drug delivery system that induces neovascularization and migration of endogenous preadipocytes (it is worth noting that ASCs can also be referred to as preadipocytes, due to their facile differentiation into adipocytes), followed by proliferation and differentiation into adipocytes. Subcutaneous lesion injections of SGMs in Wistar rats were evaluated after 6 weeks. The total lipid content extracted from the experimental group receiving FGF-2, insulin, and IGF-1 SGMs were significantly higher than groups receiving insulin SMGs alone, IGF-1 SGMs alone, and insulin/IGF-1 combined SGMs (Masuda et al., 2004).

Additional proposed therapies for improved retention and tissue restoration in AFG are the use of the stromal vascular fraction (SVF) and/or ASCs. SVF can be acquired during enzymatic collagenase digestion of excised human fat (Philips et al., 2012; Minteer et al., 2015). Clinically, SVF is attractive due to its isolation from tissue within $\sim 60-90 \mathrm{~min}$. If the SVF is placed in culture, the ASCs adhere to the surface of tissue culture treated flask after $6-8 \mathrm{~h}$ of incubation at $37^{\circ} \mathrm{C}$ and $5 \%$ $\mathrm{CO}_{2}$. When SVF or ASC cells are mixed with the fat graft, the strategy is known as cell-assisted lipotransfer (CAL). Recently, Olenczak et al. (2017) reported the supplementation of fat grafts with SVF implanted into the scalp of a NOD-SCID mouse model. At 12 weeks, the mean volume of the human adipose tissue grafts with SVF did not show improved retention compared to control fat grafts alone. Histological results also showed no improvement in the frequency of cysts, fibrosis, or inflammation from the use of SVF. However, a human clinical trial recently conducted by Gontijo-de-Amorim et al. (2017) had contrasting results. Patients in the clinical trial had symmetric depletion of the facial volume and were randomly assigned a single-session of autologous fat transfer with adipose tissue alone (control) or adipose tissue combined with SVF cell pellet (enriched). Computed tomography results found that the enriched group had significantly better volume retention ( $9.6 \%$ volume loss vs. $24 \%$ in the control group) 12 months post-operation. Potential explanations for why these two studies had contrasting results include the lack of enzymatic digestion used in the clinical trial (difference in SVF isolation protocol) (Lockhart et al., 2017), the "xenograft vs. autograft" designation, and the amount of ASC content in each SVF.

While the previous two studies provide conflicting results, there is a substantial amount of evidence supporting the therapeutic use of ASCs to improve long-term graft survival and retention (Zhu et al., 2010; Philips et al., 2014). For example, Zhu et al. (2010) studied long-term graft retention in a mouse fat transplantation model with ASCs up to 9 months. Improved graft retention, higher capillary density, and reduction in cyst formation was observed in the fat transfer groups containing ASCs after 6 and 9 months. KØlle et al. (2013) studied the efficacy of CAL in humans in the first randomized controlled study providing proof-of-principle for ex vivo expanded ASCs (Minteer et al., 2015). MRI results concluded the ASC-enriched fat grafts had significantly higher residual volumes compared to the control fat grafts with $80.9 \%$ vs. $16.3 \%$ of the initial volume 121 days from the surgical procedure. It is hypothesized that the angiogenic induction and minimal metabolic requirements by ASC contribute to the improved long-lasting graft results being observed. However, the field has yet to fully comprehend the molecular mechanisms of the role of ASCs in enhanced fat graft volume retention (Philips et al., 2014).

\section{OFF-THE-SHELF BIOTECHNOLOGIES AND SCAFFOLDS}

Implant-based soft tissue reconstruction is arguably one of the most widely studied methods to restore contour at an adipose defect site (Schmauss et al., 2016). These implants are normally used in patients who want to avoid additional scars or cannot adequately donate adipose graft tissue. However, implant-based reconstructions are prone to develop local complications within 10 years, resulting in risks as high as $70 \%$ for additional surgery (Gabriel et al., 1997; Schmauss et al., 2016). Potential off-theshelf biotechnologies such as tissue engineered scaffolds have the potential to greatly reduce the risk and complication of synthetic implants.

Scaffolds developed for permanently restoring soft tissue defects will need to consistently meet several standards while avoiding certain detrimental properties. Scaffolds should support cell attachment, migration, cell-cell interactions, cell proliferation, and cell differentiation (Brown et al., 2010; Bencherif et al., 2012; Londono and Badylak, 2015). The construct should be biocompatible with a controlled biodegradation rate proportional to newly developed adipose tissue integrating to the host environment. During the initial stages of tissue regrowth, scaffolds should provide mechanical support for cells and newly formed extracellular matrix (ECM). An interconnected network of pores should also be established to promote angiogenesis and nutrient diffusion (Teti, 1992; Keane et al., 2012). Some characteristics to avoid would include high resorption rates, foreign-body reaction, and capsular contracture. In response 
to the ideal adipose tissue scaffold, the host environment will eventually establish healing cues and have limited foreign-body reactions to the implant material (Aamodt and Grainger, 2016). This constructive remodeling response occurs with the help of selective components within the inflammatory, proliferation, and remodeling phase. The next several sections describe three different categories of biomaterials.

\section{Synthetic Biomaterial-Based Therapies}

Synthetic biomaterials have the advantage of being tailored and specifically designed for adjustment of mechanical/chemical properties as well as degradation (Place et al., 2009). Synthetic materials such as poly(lactic acid) (PLA), poly(glycolic acid) (PGA), and poly(lactic-co-glycolic acid) (PLGA) have been extensively investigated and used for adipose tissue regeneration (Patrick et al., 1999, 2002; Patrick, 2001; Place et al., 2009; Itoi et al., 2010; Dhandayuthapani et al., 2011; Sharma et al., 2015; Elamparithi et al., 2016). These polymers degrade via hydrolysis and their degradability can be controlled by altering the molecular weight, crystallinity, and ratio of lactic to glycolic acid subunits (Place et al., 2009).

As ASCs and SVF are used in AFG retention, these cells have also been seeded within scaffold biomaterials as a therapy for adipose tissue engineering. Patrick et al. (2002) demonstrated in vivo tissue formation compared preadipocyte-seeded PLGA scaffolds to acellular PLGA scaffolds implanted subcutaneously on the dorsal aspect of Lewis rats for 12 months. Histological assessment of explanted constructs showed maximum adipose tissue formation at 2 months for both groups. However, as PLGA scaffolds degraded, adipose tissue volume also deceased with time. Long term maintenance of viable adipose tissue was not obtained using the preadipocyte-seeded PLGA scaffolds (Patrick et al., 1999, 2002). Cho et al. (2005), continued to analyze synthetic biomaterials to engineer adipose tissue using PLA reinforced PGA. The biodegradable PGA/PLA support scaffold was supplemented with fibrin matrix and seeded with human adipocytes prior to implantation into subcutaneous pockets of athymic mice. After 6 weeks, adipose tissue formation with scaffold-fibrin matrix containing preadipocytes indicated differentiation in vivo. Implanted scaffolds without preadipocytes in fibrin gel demonstrated limited adipocyte formation (Cho et al., 2005). The survival of adipose tissue past 6 weeks was not reported. It is possible that an immunocompetent animal model with autologous cells may provide additional information into the mechanism. These preliminary studies introduced the use of preadipocytes for adipose tissue formation. Several limitations such as time, feasibility, and reproducibility have been addressed by investigators. With the maximum adipose tissue formation being shown at 2 months, additional therapeutics are needed to provide stronger outcomes in vivo with synthetically based scaffolds. Synthetic materials possess several drawbacks when compared to their natural counterparts, particularly the absence of intrinsic surface ligands for cell attachment and a potential impact of their degradation products on cell function (Place et al., 2009; Dhandayuthapani et al., 2011). These limitations render the use of solely biomaterials for soft tissue repair quite challenging.

\section{Natural Biomaterial-Based Therapies}

Collagen and hyaluronic acid are two of the most common naturally derived biomaterials for scaffolds in tissue engineering. The enzymatically degradable glycosaminoglycan, hyaluronic acid (HA), consists of multiple repeating disaccharide units of $\mathrm{N}$-acetyl-D-glucosamine and D-glucuronic acid. HA is a major component of the extracellular matrix due to its prominent role in cellular behavior, mechanical support, nutrient diffusion, high water retention, and intrinsic swelling property. HA-based scaffolds are currently available on the market for various surgical procedures (Stillaert et al., 2008; Itoi et al., 2010; Cohen et al., 2013).

The potential of HA as an off-the shelf biomaterial for adipose tissue growth has been studied by several research groups. Tan, et al. developed an injectable thermosensitive HA gel that confirmed in situ gel formation after subcutaneous injection into athymic mice up to 5 days (Tan et al., 2009). However, HA has been known to undergo rapid absorption in vivo (Hemmrich et al., 2008; Okabe et al., 2009). A composite device involving an HA-based $\left(\mathrm{HYAFF}^{\circledR} 11\right)$ pre-adipocyte seeded scaffold implanted in subcutaneous pockets of human volunteers, using a $1 \mathrm{~cm}$ median sub-umbilical skin incision, up to 16 weeks, has been reported (Stillaert et al., 2008). Histological analysis results indicated that the HA-based scaffold with and without preadipocyte seeding lacked evidence of any mature adipocytes at 16 weeks. In summary, the results confirm the current proposed composite scaffolds are not inductive toward adipose tissue formation with deficient angiogenic infiltration (Itoi et al., 2010).

Enhancing the adipogenic properties of hydrogels may be achieved by combining drugs or cytokines. For example, Fan et al. (2015) attempted to improve adipose tissue formation in HA hydrogels through aqueous Diels-Alder chemistry. The HA hydrogel was functionalized for a sustained release of dexamethasone over a 2-week time period. In vitro studies conveyed significant increases of the ASC population in groups containing the functionalized Dex-HA hydrogel compared HA gels after 14 days. The same mechanism of drug release was used in magnetic HA nanospheres capable of delivering dexamethasone controlled by an external magnetic field (Jia et al., 2015). In vitro ASC culture results confirmed an increase in cell viability and activity with magnetic HA nanospheres with Dex under a magnetic field. Controlled drug/biomolecule delivery continues to be an evolving asset in tissue restorative therapies.

Collagen is a naturally derived ECM protein that provides biodegradability, biocompatibility, and weak antigenicity. Several collagenous based biomaterials have been studied due to their favorable characteristics, long history of safety, and FDA-approval. One of the earliest studies of collagen and FGF-2 therapy reported the use of reconstituted basement membrane extracellular matrix, Matrigel ${ }^{\mathrm{TM}}$, to deliver FGF-2 subcutaneously in BALB/c nude mice at several concentrations (Kawaguchi et al., 1998). Experimental groups receiving Matrigel $^{\mathrm{TM}}$ supplemented with FGF-2 at 10, 100, and $1000 \mathrm{ng} / \mathrm{ml}$, saw neovascularization within 7 days, followed by migration of endogenous preadipocytes. A visible fat pad was observed between 1 and 2 weeks and was maintained up to 10 weeks (Kawaguchi et al., 1998). An alternative to free FGF-2 delivery 
has been investigated in gelatin microspheres containing $1 \mu \mathrm{g}$ incorporated in the Matrigel ${ }^{\mathrm{TM}}$ scaffold along with ASCs (Kimura et al., 2003). Using a BALB/c nude mouse model, a significant difference in adipose tissue formation was discovered using gelatin microsphere encapsulated FGF-2 compared to free FGF-2 in the collagen sponge subcutaneous implant. Additionally, the most adipose tissue was formed using $2.5 \times 10^{4}$ ASCs $/ \mathrm{cm}^{2}$ of the implant site compared to $1.25 \times 10^{4}$ and $5 \times 10^{3}$ cells $/ \mathrm{cm}^{2}$ (Kimura et al., 2003).

Matrigel $^{\mathrm{TM}}$ has also been investigated with alginate microbeads containing fibroblast growth factor-1 (FGF-1) to induce neovascularization and adipogenesis in a rat vascular pedicle model of adipose tissue engineering (material of interest deposited in silicone tube with vasculature wrapped in local fat pad) (Moya et al., 2010). Vessel density and area of adipose tissue was measured are 6 weeks. Compared to a bolus injection of FGF-1 and empty alginate microbeads, Matrigel ${ }^{\mathrm{TM}}$ containing $2.5 \mu \mathrm{g} / \mathrm{ml}$ of FGF-1 in microbeads experienced higher rates of vessel density. However, no difference in adipose tissue formation was observed between the bolus injection group and FGF-1 microbeads group at $2.5 \mu \mathrm{g} / \mathrm{ml}$ dose (Moya et al., 2010).

Porous collagenous microbeads (CultiSphers; Sigma, St. Louis, MO, United States) have been evaluated as an injectable cell delivery scaffold for ASCs (Rubin et al., 2007). In vitro studies using a spinner flask showed ASCs in culture attach and seed into microbeads at a high capacity. The ability to proliferate and differentiate was also confirmed with clear potential in culture up to 49 and 21 days, respectively (Rubin et al., 2007). An assessment of cell viability post-injection and tissue growth in vivo are the logical next steps to advance this technology for adipose tissue regeneration. Since these early studies, there have been multiple in vivo studies examining collagen in adipose tissue engineering (von Heimburg et al., 2001; Kimura et al., 2003; Vashi et al., 2006; Itoi et al., 2010; Cherubino et al., 2016).

While the majority of studies with collagen consisted of bovine collagen, salmon collagen has also been evaluated as a scaffold for its ligand protein interactions. This protein biomaterial was prepared with and without pioglitazone, a known inducer of adipogenesis via PPAR- $\gamma$ (Yazawa et al., 2015). Using a $\mathrm{C} 3 \mathrm{H} / \mathrm{He} / \mathrm{N}$ mouse model, biomaterials were injected subcutaneously and analyzed at 1 and 4 weeks. Histological results showed mature adipocyte growth substituting the pioglitazone collagen after 4 weeks compared to minimal tissue growth in the control group without pioglitazone.

While scaffold performance of collagen and $\mathrm{HA}$ has been analyzed individually, the combined form of these natural biomaterials have implications on the future use of multi-component scaffold. Collagen (type I, derived from bovine Achilles) and HA (derived from bovine vitreous humor) has been crosslinked to develop a three-dimensional scaffold that encourages adipose tissue development (Davidenko et al., 2010). Collagen-HA scaffolds were characterized, seeded with preadipocytes, and compared to collagen scaffolds. The results indicated that collagen-HA significantly increased gene expression of adipsin, an enzyme involved in lipid metabolism predominately in mature adipocytes ( $\mathrm{Lu}$ et al., 2014), and noticeably higher levels of PPAR- $\gamma$. The inclusion of HA in collagen scaffolds may aid adipogenesis by hastening cell-contacted growth arrest prior to adipogenic conversion (Davidenko et al., 2010). Preadipocytes seeded on collagen coated with elastin has also been recognized as a potential scaffold with the ability to encourage cell proliferation, infiltration, and adhesion (Keck et al., 2011).

Gelatin, a partially degraded product of collagen, contains amino acid sequences, which can enhance cell attachment (Chang et al., 2013). Gelatin has also been combined with hyaluronic acid as a complementary ingredient for cryogel scaffolds. Gelatin-HA cryogel scaffolds were seeded with porcine ASCs and implanted into the subcutaneous pocket of two separate animal models: murine and porcine. Acellular cryogels were also implanted for comparison. The relative gene expression of adipocyte-specific genes (PPAR- $\gamma, \mathrm{LPL}, \mathrm{aP} 2$, and leptin) were significantly greater in the seeded gelatin-HA scaffolds than acellular scaffolds at weeks 2 , 4 , and 8 in both animal models. It is important to note that both seeded and acellular scaffolds exhibited positive CD31 staining at 8 weeks showing how adequate porosity sufficiently provided space for vascularization in the acellular scaffold implants, a characteristic many other acellular scaffolds failed to demonstrate (Chang et al., 2013).

Chitosan (CS) is another biodegradable natural material currently being used in tissue engineering applications (Tan et al., 2010; Wang et al., 2013a,b). The biocompatible characteristics of cell adhesion and growth were determined using crosslinked CS with poly (L-glutamic acid) to mimic natural ECM (Wang et al., 2013a). A porous scaffold was developed via lyophilization for evaluation of engineered adipose tissue in SCID mice. Acellular and ASC-seeded scaffolds were implanted. After 6 weeks, scaffolds remain intact with vascularization reported in the cell-seeded scaffolds. Cell-seeded poly (L-glutamic acid)/CS scaffolds retained $90 \%$ volume and Oil red O staining indicated adipose tissue formation within the implant (Wang et al., 2013a). Minimal adipose tissue was formed within acellular implants. CS has also been crosslinked with HA to produce an injectable hydrogel scaffold capable of delivering dexamethasone for adipose tissue growth (Sun et al., 2013). Test results in ASC culture revealed dexamethasone as an important factor in hydrogel performance with increased proliferation and cell adhesion.

Silk is another widely examined biomaterial for soft tissue repair. Silk is a naturally occurring biocompatible protein with tunable mechanical strength, adjustable degradation rate, and low inflammatory and immunogenic responses (Bellas et al., 2015; Abbott et al., 2016). In reference to the application of silk to soft tissue regeneration, Bellas et al. (2015) evaluated silk at three concentrations in the form of an injectable foam scaffold. Silk foams supported in vitro ASC survival and migration over a 10-day period. Subcutaneous injections of silk scaffolds in Sprague-Dawley rats demonstrated significant degradation after 90 days with new tissue formation, and cell-seeding ASCs into the silk scaffold may have contributed to new adipose tissue growth in vivo.

Overall, the use of natural-biomaterial based therapies has led to considerably positive results both in vitro and in vivo. The 
use of ASCs for in vivo injection studies showed significance on several examples. More comparison studies of natural biomaterials containing ASCs with different therapeutic agents in vivo would be immensely revealing to see if a specific grouping is ideal.

\section{Extracellular Matrix (ECM) Biomaterial-Based Therapies}

An ECM scaffold-based approach to regeneration will elicit an immediate host response distinctly different from other scaffold materials after implantation in vivo due to their surface topologies and ligand landscapes (Brown et al., 2012b). Cellular infiltrate consisting of polymorphonuclear leukocytes and mononuclear cells occurs within min. After $72 \mathrm{~h}$, most infiltrating cells are entirely mononuclear, specifically of the pro-inflammatory macrophage phenotype (M1), with early signs of neovascularization. For 2 weeks, the mononuclear cell population continues to infiltrate the ECM scaffold, including macrophages for apoptotic neutrophil removal, angiogenesis dramatically increases, and degradation of scaffold is advanced as newly formed host ECM is deposited. By day 14, a reduced mononuclear cell population consisting mostly of immunoregulatory macrophage phenotype (M2) resides and site specific parenchymal cells appear to begin the final phase of constructive remodeling along with circulating, marrow derived progenitor cells. By day 35 , there should be minimal to no scaffold present and a dense, highly organized connective tissue present (Badylak, 2002, 2004; Brown et al., 2012a,b).

Despite a multitude of publications investigating the use of synthetic and natural materials for adipose tissue engineering, there remains a clinical need to have an off-the-shelf biomaterial for adipose restoration. Recent advances in decellularization have provided researchers an alternative material to employ in all areas of tissue engineering. Ideally, decellularization is designed to remove the immunogenic material from donated biological sources while retaining as many constitutive components as possible. ECM can be derived from a specific tissue source to exploit its unique assortment of endogenous factors to restore its respective milieu. Many endogenous factors such as VEGF, transforming growth factor (TGF) beta 1, basic fibroblast growth factor, placenta growth factor and insulinlike growth factor 1 affecting angiogenesis have been identified in adipose tissues (Choi et al., 2014). Decellularized adipose tissue (DAT) has gained significance in the tissue regeneration field as scaffold material in the form of hydrogels, sponges, injectable hydrated material, and fibers constructed from adipose ECM.

Several groups have validated DAT hydrogel from human and porcine as a support structure for cellular activity in vitro (Uriel et al., 2008; Choi et al., 2011, 2014; Young et al., 2011; Poon et al., 2013; Sano et al., 2014). The investigation of porcine adipose ECM utilized freeze-thaw cycles along with trypsin/EDTA to decellularize porcine tissue. Resultant porcine derived biomaterial demonstrated DNA content $99.5 \%$ less than native tissue and successful cellular infiltration in vitro over 8 days. However, the lack of animal research for adipose growth undermines its actual potential (Roehm et al., 2016). A pepsin digest was used to create an injectable hydrogel from dry milled human DAT; endogenous proteins like collagen I, III, and IV were present after processing (Young et al., 2011). Gelation of the hydrogel occurred with subcutaneous bolus injections in athymic mice. However, implants were excised $15 \mathrm{~min}$ later and further points in time were not investigated. In a later publication, this research was updated to include an ASC-seeded scaffolds with or without transglutaminase (TG), an angiogenic cross-linker (Adam Young et al., 2014). It was discovered that the addition of TG and ASCs significantly improved vascularization in vivo compared to the human DAT hydrogel. Oil red O staining of the scaffolds after 4 weeks in vivo also indicated superior adipogenesis in human DAT hydrogel containing TG and ASCs (Adam Young et al., 2014).

It has been hypothesized that adipose derived stem cells in combination with DAT would be therapeutic for stimulating natural soft tissue regeneration. Several groups have investigated this hypothesis including the fabrication of an injectable microparticle formulation in saline for engineered fat graft evaluation. Human ASCs (hASCs) were combined with human DAT to study adipose tissue engineering implanted subcutaneously in nude rats for up to 8 weeks compared to human fat graft and hASC injection. Vessel density confirmed by IHC staining showed that human DAT-ASCs grafts at 4 and 8 weeks contained less vessels compared to the fresh human fat grafts. H\&E staining also confirmed remodeling of fresh graft and surrounding tissue resembling new adipose formation (Wang et al., 2013). In a cell culture comparison study, ASCs were induced in adipogenic media for 2 weeks and seeded onto various scaffolds (type I collagen sponge, PGA, and hyaluronic acid) prior to implantation into athymic mice. Compared to ASCs seeded in normal culture media in various scaffolds, the area of newly generated adipose tissue was significantly increased in the induced ASCs group. However, within the induced ASC group, only the type I collagen sponge displayed noticeable amounts of adipogenesis after 8 weeks. Induced ASCs in PGA and hyaluronic acid gel displayed minimal adipocyte growth (Itoi et al., 2010). In summary, the results confirm the current proposed composite scaffolds are not inductive toward adipose tissue formation with deficient angiogenic penetration (Itoi et al., 2010).

As a strategy to increase clinical relevance, Han et al. assessed allogenic rat ASC-seeded DAT scaffolds implanted subcutaneously in an immunocompetent Wistar rat model. Cells were seeded $72 \mathrm{~h}$ prior to implantation (Han et al., 2015). Compared to non-seeded scaffolds, significant remodeling into mature adipocytes was observed in the ASC-seeded groups at 8 and 12 weeks. Adipogenic marker expression in surrounding macrophages confirmed these results as well as correlated increases blood vessel diameter at 12 weeks. The scaffold platform proposed in this study provides invaluable preclinical data toward clinical trials (Han et al., 2015).

Specific ECM and cellular parameters can be adjusted to influence cellular behavior. For example, the effect of DAT particle size and cell density on ASC proliferation 
and differentiation was assessed in a composite methacrylate chondroitin sulfate (MSC)-DAT hydrogel. At a cellular density of 2500 cells/ $\mu 1$ of MSC-DAT hydrogel, proliferation of human ASCs was significantly higher than using DAT of large particle size $(\sim 280 \mu \mathrm{m})$ compared to the small particle size group $(\sim 40 \mu \mathrm{m})$. However, at an ASC concentration of 5000 cells/ $\mu$ l of hydrogel, the small particle size group displayed a significantly outperformed all groups with the greatest amount of adipogenesis, identified by glycerol-3-phosphate dehydrogenase activity and laminin production (Brown et al., 2015).

In an attempt to enhance fat graft volume retention, FGF2 was loaded into an injectable decellularized adipose matrix (mouse-derived tissue) to be investigated as a potential softtissue replacement for reconstructive surgery (Zhang et al., 2016). A 12-week animal study compared to performance of FGF-2Loaded DAT to PBS hydrated DAT in the form of subcutaneous injections. Results indicated significantly more adipose neotissue formation and higher volume retention at 6 weeks in the FGF2 group. Adipocyte quantifications at 12 weeks for the FGF2-loaded group were also comparable to endogenous mouse adipose (Zhang et al., 2016).

The use of decellularized ECM from tissues other than adipose have also been examined for soft tissue repair. For example, PLGA microspheres containing FGF-2 were combined with decellularized small intestinal submucosa (SIS) particulates and ASCs in an athymic mouse subcutaneous model for adipose tissue growth (Marra et al., 2008). Initially, ASCs were cultured and allowed to proliferate on SIS particulate before injection. Following the SIS injection, mice received either $1 \mathrm{ng}$ of free FGF-2, $1 \mathrm{ng}$ dose of FGF-2 in PLGA microspheres, or no FGF-2. Blood vessel quantification was significantly higher in mice receiving FGF-2 microspheres (Marra et al., 2008).

\section{ANIMAL MODELS FOR ADIPOSE TISSUE REPAIR}

A variety of animals has been used in adipose tissue research, each serving a specific purpose. Athymic mice are frequently used to assess volume retention of human fat grafts under various experimental conditions (microspheres) as well as the growth/differentiation of human ASCs in scaffolds within a living system. Athymic mice provide the advantage of physiological conditions for a multi-week study without having to match cellto-animal species. Substantial information can be obtained from these studies, but it is distant from clinical application in terms of size, function, and immune health.

The use of an immunocompetent animal such as the Wistar rat is also common. The use of allogenic cells, autologous fat, and multi-component scaffolds have been explored and evaluated in the Wistar rat model. Materials are normally injected as a bolus subcutaneously with studies lasting up to 12 weeks. An animal model with a healthy immune system allow investigators to fully consider material degradation and immune responses related to adipose tissue formation. Adipose volume retention has been reported in this animal model at 12 weeks (Topcu et al., 2012), providing significant data with some clinical relevance. However, adipose defect repair has yet to be implemented in the Wistar rat, which would more closely reflect the clinical need.

It would be useful to identify an animal model that reflects the nature of an adipose defect where subcutaneous tissue is removed and a potential scaffold is implanted to demonstrate inherent tissue regeneration. Some animals that could be appropriate for this model would be the rabbit, guinea pig, or pig. These animal models would also be appropriate to assess different size defects to identify any size limitations for a potential regenerative scaffold. Once a desirable biomaterial has been established, investigators must be able to approximately quantify the amount of tissue formation per concentration of drug and/or biological factors within scaffold of choice on top of the optimal cell concentration. These results and parameters are critical for translation of these biotechnologies as well as their appropriate application to an array of unique adipose defect cases in the clinic.

\section{CONCLUSION}

The investigation of various therapies for sustained adipose tissue regeneration has advanced significantly since AFG was introduced by Neuber (1893) and Tabit et al. (2012). Early on, clinicians saw the limitations of AFG and sought ways to work with researchers to improve patient outcomes. While AFG enhancement strategies have significantly improved, investigators continue to seek the benefits of establishing offthe-shelf biotechnologies for adipose tissue repair. Some of the earliest studies exploited the principles of synthetic, manmade materials for constructing implants and scaffolds that were temporary solutions to the lack of functional adipose tissue. Naturally derived biomaterials and decellularized proteins are currently prevalent in the research area as the base component of biologically active therapeutic strategies. From the beginning, ASCs have shown an important role being that these undifferentiated precursor cells provide the appropriate population for neovascularization and adipocyte formation. It is anticipated that biodegradable biomaterials will continue to dominate the future of tissue engineering, specifically adipose tissue. These complex, multi-component scaffolds require several fabrication steps to develop each component. With this degree of complexity involved in fabricating each scaffold, consistency and standardized batch testing will be of immense importance. Although these factors are in the preclinical stage, the addition of personnel with controlled drug delivery as well as manufacturing experience in the research lab can give investigators a clear advantage for the implementation of their complex biomaterial technology.

\section{AUTHOR CONTRIBUTIONS}

CM summarized the literature, wrote the review, drew the figure, and constructed the table. CI summarized literature related to biomolecules for adipose tissue repair. CY and KM provided critical comments on content. 


\section{FUNDING}

This review is based upon work supported by the National Institute of Biomedical Imaging and Bioengineering of the

\section{REFERENCES}

Aamodt, J. M., and Grainger, D. W. (2016). Extracellular matrix-based biomaterial scaffolds and the host response. Biomaterials 86, 68-82. doi: 10.1016/j. biomaterials.2016.02.003

Abbott, R. D., Wang, R. Y., Reagan, M. R., Chen, Y., Borowsky, F. E., Zieba, A., et al. (2016). The use of silk as a scaffold for mature, sustainable unilocular adipose 3D tissue engineered systems. Adv. Healthc. Mater. 5, 1667-1677. doi: 10.1002/adhm.201600211

Adam Young, D., Bajaj, V., and Christman, K. L. (2014). Award winner for outstanding research in the $\mathrm{PhD}$ category, 2014 society for biomaterials annual meeting and exposition, denver, colorado, April 16-19, 2014: decellularized adipose matrix hydrogels stimulate in vivo neovascularization and adipose formation. J. Biomed. Mater. Res. Part A 102, 1641-1651. doi: 10.1002/jbm.a. 35109

Agha, R. A., Goodacre, T., and Orgill, D. P. (2013). Use of autologous fat grafting for reconstruction postmastectomy and breast conserving surgery: a systematic review protocol. BMJ Open 3:e003709. doi: 10.1136/bmjopen-2013-003709

ASPS (2017). "2016 Reconstructive Demographics," in 2016 Plastic Surgery Statistics Report (Arlington Heights, IL: American Society of Plastic Surgeons Public Relations).

Badylak, S. F. (2002). The extracellular matrix as a scaffold for tissue reconstruction. Semin. Cell Dev. Biol. 13, 377-383. doi: 10.1016/S1084952102000940

Badylak, S. F. (2004). Xenogeneic extracellular matrix as a scaffold for tissue reconstruction. Transpl. Immunol. 12, 367-377. doi: 10.1016/j.trim.2003.12.016

Bellas, E., Lo, T. J., Fournier, E. P., Brown, J. E., Abbott, R. D., Gil, E. S., et al. (2015). Injectable silk foams for soft tissue regeneration. Adv. Healthc. Mater. 4, 452-459. doi: 10.1002/adhm.201400506

Bencherif, S. A., Sands, R. W., Bhatta, D., Arany, P., Verbeke, C. S., and Edwards, D. A. (2012). Injectable preformed scaffolds with shape-memory properties. Proc. Natl. Acad. Sci. U.S.A. 109, 19590-19595. doi: 10.1073/pnas.1211516109

Bourne, D. A., James, I. B., Wang, S. S., Marra, K. G., and Rubin, J. P. (2016). The architecture of fat grafting: what lies beneath the surface. Plast. Reconstr. Surg. 137, 1072-1079. doi: 10.1097/01.prs.0000479992.10986.ad

Brown, B. N., Barnes, C. A., Kasick, R. T., Michel, R., Gilbert, T. W., BeerStolz, D., et al. (2010). Surface characterization of extracellular matrix scaffolds. Biomaterials 31, 428-437. doi: 10.1016/j.biomaterials.2009.09.061

Brown, B. N., Londono, R., Tottey, S., Zhang, L., Kukla, K. A., Wolf, M. T., et al. (2012a). Macrophage phenotype as a predictor of constructive remodeling following the implantation of biologically derived surgical mesh materials. Acta Biomater. 8, 978-987. doi: 10.1016/j.actbio.2011.11.031

Brown, B. N., Ratner, B. D., Goodman, S. B., Amar, S., and Badylak, S. F. (2012b). Macrophage polarization: an opportunity for improved outcomes in biomaterials and regenerative medicine. Biomaterials 33, 3792-3802. doi: 10.1016/j.biomaterials.2012.02.034

Brown, C. F., Yan, J., Han, T. T., Marecak, D. M., Amsden, B. G., and Flynn, L. E. (2015). Effect of decellularized adipose tissue particle size and cell density on adipose-derived stem cell proliferation and adipogenic differentiation in composite methacrylated chondroitin sulphate hydrogels. Biomed. Mater. 10:045010. doi: 10.1088/1748-6041/10/4/045010

Chang, K.-H., Liao, H.-T., and Chen, J.-P. (2013). Preparation and characterization of gelatin/hyaluronic acid cryogels for adipose tissue engineering: In vitro and in vivo studies. Acta Biomater. 9, 9012-9026. doi: 10.1016/j.actbio.2013. 06.046

Cherubino, M., Valdatta, L., Balzaretti, R., Pellegatta, I., Rossi, F., Protasoni, M., et al. (2016). Human adipose-derived stem cells promote vascularization of collagen-based scaffolds transplanted into nude mice. Regen. Med. 11, 261-271. doi: 10.2217/rme-2015-0010

Cheung, H. K., Han, T. T., Marecak, D. M., Watkins, J. F., Amsden, B. G., and Flynn, L. E. (2014). Composite hydrogel scaffolds incorporating decellularized
National Institutes of Health under Award Nos. F31EB022425 and T32EB102612. The content is solely the responsibility of the authors and does not necessarily represent the official views of the National Institutes of Health.

adipose tissue for soft tissue engineering with adipose-derived stem cells. Biomaterials 35, 1914-1923. doi: 10.1016/j.biomaterials.2013.11.067

Cho, S.-W., Kim, S.-S., Rhie, J. W., Cho, H. M., Choi, C. Y., and Kim, B.-S. (2005). Engineering of volume-stable adipose tissues. Biomaterials 26, 3577-3585. doi: 10.1016/j.biomaterials.2004.09.013

Choi, J. S., Choi, Y. C., Kim, J. D., Kim, E. J., Lee, H. Y., Kwon, I. C., et al. (2014). Adipose tissue: a valuable resource of biomaterials for soft tissue engineering. Macromol. Res. 22, 932-947. doi: 10.1007/s13233-014-2135-5

Choi, J. S., Kim, B. S., Kim, J. Y., Kim, J. D., Choi, Y. C., Yang, H.-J., et al. (2011). Decellularized extracellular matrix derived from human adipose tissue as a potential scaffold for allograft tissue engineering. J. Biomed. Mater. Res. Part A 97A, 292-299. doi: 10.1002/jbm.a.33056

Chung, C. W., Marra, K. G., Li, H., Leung, A. S., Ward, D. H., Tan, H., et al. (2012). VEGF microsphere technology to enhance vascularization in fat grafting. Ann. Plast. Surg. 69, 213-219. doi: 10.1097/SAP.0b013e3182573827

Cohen, J. L., Dayan, S. H., Brandt, F. S., Nelson, D. B., Axford-Gatley, R. A., Theisen, M. J., et al. (2013). Systematic review of clinical trials of smalland large-gel-particle hyaluronic acid injectable fillers for aesthetic soft tissue augmentation. Dermatol. Surg. 39, 205-231. doi: 10.1111/dsu.12036

Davidenko, N., Campbell, J. J., Thian, E. S., Watson, C. J., and Cameron, R. E. (2010). Collagen-hyaluronic acid scaffolds for adipose tissue engineering. Acta Biomater. 6, 3957-3968. doi: 10.1016/j.actbio.2010.05.005

Dhandayuthapani, B., Yoshida, Y., Maekawa, T., and Kumar, D. S. (2011). Polymeric scaffolds in tissue engineering application: a review. Int. J. Polym. Sci. 2011:290602. doi: 10.1155/2011/290602

Elamparithi, A., Punnoose, A. M., Kuruvilla, S., Ravi, M., Rao, S., and Paul, S. F. (2016). Electrospun polycaprolactone matrices with tensile properties suitable for soft tissue engineering. Artif. Cells Nanomed. Biotechnol. 44, 878-884. doi: 10.3109/21691401.2014.998825

Fan, M., Ma, Y., Zhang, Z., Mao, J., Tan, H., and Hu, X. (2015). Biodegradable hyaluronic acid hydrogels to control release of dexamethasone through aqueous Diels-Alder chemistry for adipose tissue engineering. Mater. Sci. Eng. C Mater. Biol. Appl. 56, 311-317. doi: 10.1016/j.msec.2015.04.004

Gabriel, S. E., Woods, J. E., O’Fallon, W. M., Beard, C. M., Kurland, L. T., and Melton, L. J. III (1997). Complications leading to surgery after breast implantation. N. Engl. J. Med. 336, 677-682. doi: 10.1056/ nejm199703063361001

Gir, P., Brown, S. A., Oni, G., Kashefi, N., Mojallal, A., and Rohrich, R. J. (2012a). Fat grafting: evidence-based review on autologous fat harvesting, processing, reinjection, and storage. Plast. Reconstr. Surg. 130, 249-258. doi: 10.1097/PRS. 0b013e318254b4d3

Gir, P., Oni, G., Brown, S. A., Mojallal, A., and Rohrich, R. J. (2012b). Human adipose stem cells: current clinical applications. Plast. Reconstr. Surg. 129, 1277-1290. doi: 10.1097/PRS.0b013e31824ecae6

Gontijo-de-Amorim, N. F., Charles-de-Sa, L., and Rigotti, G. (2017). Mechanical supplementation with the stromal vascular fraction yields improved volume retention in facial lipotransfer: a 1-year comparative study. Aesthet. Surg. J. 37, 975-985. doi: 10.1093/asj/sjx115

Han, T. T., Toutounji, S., Amsden, B. G., and Flynn, L. E. (2015). Adipose-derived stromal cells mediate in vivo adipogenesis, angiogenesis and inflammation in decellularized adipose tissue bioscaffolds. Biomaterials 72, 125-137. doi: 10.1016/j.biomaterials.2015.08.053

Hemmrich, K., Van de Sijpe, K., Rhodes, N. P., Hunt, J. A., Di Bartolo, C., Pallua, N., et al. (2008). Autologous in vivo adipose tissue engineering in hyaluronanbased gels a pilot study. J. Surg. Res. 144, 82-88. doi: 10.1016/j.jss.2007. 03.017

Hong, S. J., Lee, J. H., Hong, S. M., and Park, C. H. (2010). Enhancing the viability of fat grafts using new transfer medium containing insulin and $\beta$-fibroblast growth factor in autologous fat transplantation. J. Plast. Reconstr. Aesthet. Surg. 63, 1202-1208. doi: 10.1016/j.bjps.2009.05.040 
Hutley, L., Shurety, W., Newell, F., McGeary, R., Pelton, N., Grant, J., et al. (2004). Fibroblast growth factor 1: a key regulator of human adipogenesis. Diabetes Metab. Res. Rev. 53, 3097-3106. doi: 10.2337/diabetes.53.12.3097

Itoi, Y., Takatori, M., Hyakusoku, H., and Mizuno, H. (2010). Comparison of readily available scaffolds for adipose tissue engineering using adipose-derived stem cells. J. Plast. Reconstr. Aesthet. Surg. 63, 858-864. doi: 10.1016/j.bjps.2009. 01.069

Jia, Y., Fan, M., Chen, H. N., Miao, Y. T., Xing, L., Jiang, B. H., et al. (2015). Magnetic hyaluronic acid nanospheres via aqueous Diels-Alder chemistry to deliver dexamethasone for adipose tissue engineering. J. Colloid Interface Sci. 458, 293-299. doi: 10.1016/j.jcis.2015.07.062

Jiang, A., Li, M., Duan, W., Dong, Y., and Wang, Y. (2015). Improvement of the survival of human autologous fat transplantation by adipose-derived stem-cells-assisted lipotransfer combined with bFGF. ScientificWorldJournal 2015:968057. doi: 10.1155/2015/968057

Kaufman, M. R., Miller, T. A., Huang, C., Roostaeian, J., Wasson, K. L., Ashley, R. K., et al. (2007). Autologous fat transfer for facial recontouring: is there science behind the art? Plast. Reconstr. Surg. 119, 2287-2296. doi: 10.1097/01. prs.0000260712.44089.e7

Kawaguchi, N., Toriyama, K., Nicodemou-Lena, E., Inou, K., Torii, S., and Kitagawa, Y. (1998). De novo adipogenesis in mice at the site of injection of basement membrane and basic fibroblast growth factor. Proc. Natl. Acad. Sci. U.S.A. 95, 1062-1066. doi: 10.1073/pnas.95.3.1062

Keane, T. J., Londono, R., Turner, N. J., and Badylak, S. F. (2012). Consequences of ineffective decellularization of biologic scaffolds on the host response. Biomaterials 33, 1771-1781. doi: 10.1016/j.biomaterials.2011.10.054

Keck, M., Haluza, D., Selig, H. F., Jahl, M., Lumenta, D. B., Kamolz, L. P., et al. (2011). Adipose tissue engineering: three different approaches to seed preadipocytes on a collagen-elastin matrix. Ann. Plast. Surg. 67, 484-488. doi: 10.1097/SAP.0b013e31822f9946

Kelmendi-Doko, A., Marra, K. G., Vidic, N., Tan, H., and Rubin, J. P. (2014). Adipogenic factor-loaded microspheres increase retention of transplanted adipose tissue. Tissue Eng. Part A 20, 2283-2290. doi: 10.1089/ten.tea.2012. 0701

Kelmendi-Doko, A., Rubin, J. P., Klett, K., Mahoney, C., Wang, S., and Marra, K. G. (2017). Controlled dexamethasone delivery via double-walled microspheres to enhance long-term adipose tissue retention. J. Tissue Eng. 8:2041731417735402. doi: $10.1177 / 2041731417735402$

Kim, H. J., Cha, J. Y., Seok, J. W., Choi, Y., Yoon, B. K., Choi, H., et al. (2016). Dexras1 links glucocorticoids to insulin-like growth factor-1 signaling in adipogenesis. Sci. Rep. 6:28648. doi: 10.1038/srep28648

Kim, M., Kim, I., Lee, S. K., Bang, S. I., and Lim, S. Y. (2011). Clinical trial of autologous differentiated adipocytes from stem cells derived from human adipose tissue. Dermatol. Surg. 37, 750-759. doi: 10.1111/j.1524-4725.2011. 01765.x

Kimura, Y., Ozeki, M., Inamoto, T., and Tabata, Y. (2003). Adipose tissue engineering based on human preadipocytes combined with gelatin microspheres containing basic fibroblast growth factor. Biomaterials 24, 2513-2521. doi: 10.1016/S0142-9612(03)00049-8

Kølle, S. F., Fischer-Nielsen, A., Mathiasen, A. B., Elberg, J. J., Oliveri, R. S., Glovinski, P. V., et al. (2013). Enrichment of autologous fat grafts with exvivo expanded adipose tissue-derived stem cells for graft survival: a randomised placebo-controlled trial. Lancet 382, 1113-1120. doi: 10.1016/S0140-6736(13) 61410-5

Kurita, M., Matsumoto, D., Shigeura, T., Sato, K., Harii, K., Gonda, K., et al. (2008). Influences of centrifugation on cells and tissues in liposuction aspirates: optimized centrifugation for lipotransfer and cell isolation. Plast. Reconstr. Surg. 121, 1033-1041. doi: 10.1097/01.prs.0000299384.53131.87

Largo, R. D., Tchang, L. A. H., Scherberich, A., Harder, Y., Wettstein, R., and Schaefer, D. J. (2014). Efficacy, safety and complications of autologous fat grafting to healthy breast tissue: a systematic review. J. Plast. Reconstr. Aesthet. Surg. 67, 437-448. doi: 10.1016/j.bjps.2013.11.011

Lockhart, R. A., Aronowitz, J. A., and Dos-Anjos Vilaboa, S. (2017). Use of freshly isolated human adipose stromal cells for clinical applications. Aesthet. Surg. J. 37(Suppl. 3), S4-S8. doi: 10.1093/asj/sjw270

Londono, R., and Badylak, S. F. (2015). Biologic scaffolds for regenerative medicine: mechanisms of in vivo remodeling. Ann. Biomed. Eng. 43, 577-592. doi: $10.1007 / \mathrm{s} 10439-014-1103-8$
Lu, Q., Li, M., Zou, Y., and Cao, T. (2014). Delivery of basic fibroblast growth factors from heparinized decellularized adipose tissue stimulates potent de novo adipogenesis. J. Control. Release 174, 43-50. doi: 10.1016/j.jconrel.2013. 11.007

Marra, K. G., Defail, A. J., Clavijo-Alvarez, J. A., Badylak, S. F., Taieb, A., and Schipper, B. (2008). FGF-2 enhances vascularization for adipose tissue engineering. Plast. Reconstr. Surg. 121, 1153-1164. doi: 10.1097/01.prs. 0000305517.93747 .72

Masuda, T., Furue, M., and Matsuda, T. (2004). Photocured, styrenated gelatinbased microspheres for de novo adipogenesis through corelease of basic fibroblast growth factor, insulin, and insulin-like growth factor I. Tissue Eng. 10, 523-535. doi: 10.1089/107632704323061889

Miller, A. M., Steiner, C. A., Barrett, M. L., Fingar, K. R., and Elixhauser, A. (2017). "Breast reconstruction surgery for mastectomy in hospital inpatient and ambulatory settings, 2009-2014: statistical Brief \#228," in Healthcare Cost and Utilization Project (HCUP) Statistical Briefs (Rockville, MD: Agency for Healthcare Research and Quality (US)).

Minteer, D. M., Marra, K. G., and Rubin, J. P. (2015). Adipose stem cells: biology, safety, regulation, and regenerative potential. Clin. Plast. Surg. 42, 169-179. doi: 10.1016/j.cps.2014.12.007

Monfort, A., and Izeta, A. (2012). Strategies for human adipose tissue repair and regeneration. J. Cosmet. Dermatol. Sci. Appl. 2A:22144. doi: 10.4236/jcdsa.2012. 222021

Moya, M. L., Cheng, M. H., Huang, J. J., Francis-Sedlak, M. E., Kao, S. W., Opara, E. C., et al. (2010). The effect of FGF-1 loaded alginate microbeads on neovascularization and adipogenesis in a vascular pedicle model of adipose tissue engineering. Biomaterials 31, 2816-2826. doi: 10.1016/j.biomaterials. 2009.12.053

Nahabedian, M. Y. (2015). Factors to consider in breast reconstruction. Womens Health 11, 325-342. doi: 10.2217/whe.14.85

Neuber, F. (1893). Fat transplantation. Chir Kongr. Verhandl Dsch. Ges. Chir 20:66. Okabe, K., Yamada, Y., Ito, K., Kohgo, T., Yoshimi, R., and Ued, M. (2009). Injectable soft-tissue augmentation by tissue engineering and regenerative medicine with human mesenchymal stromal cells, platelet-rich plasma and hyaluronic acid scaffolds. Cytotherapy 11, 307-316. doi: 10.1080/ 14653240902824773

Olenczak, J. B., Seaman, S. A., Lin, K. Y., Pineros-Fernandez, A., Davis, C. E., Salopek, L. S., et al. (2017). Effects of collagenase digestion and stromal vascular fraction supplementation on volume retention of fat grafts. Ann. Plast. Surg. 78(Suppl. 5), S335-S342. doi: 10.1097/sap.0000000000001063

Patrick, C. W. Jr. (2001). Tissue engineering strategies for adipose tissue repair. Anat. Rec. 263, 361-366. doi: 10.1002/ar.1113

Patrick, C. W. Jr., Chauvin, P. B., Hobley, J., and Reece, G. P. (1999). Preadipocyte seeded PLGA scaffolds for adipose tissue engineering. Tissue Eng. 5, 139-151. doi: 10.1089/ten.1999.5.139

Patrick, C. W. Jr., Zheng, B., Johnston, C., and Reece, G. P. (2002). Long-term implantation of preadipocyte-seeded PLGA scaffolds. Tissue Eng. 8, 283-293. doi: 10.1089/107632702753725049

Philips, B. J., Marra, K. G., and Rubin, J. P. (2012). Adipose stem cell-based soft tissue regeneration. Expert Opin. Biol. Ther. 12, 155-163. doi: 10.1517/ 14712598.2012 .644533

Philips, B. J., Marra, K. G., and Rubin, J. P. (2014). Healing of grafted adipose tissue: current clinical applications of adipose-derived stem cells for breast and face reconstruction. Wound Repair Regen. 22(Suppl. 1), 11-13. doi: 10.1111/ wrr. 12164

Phipps, K. D., Gebremeskel, S., Gillis, J., Hong, P., Johnston, B., and Bezuhly, M. (2015). Alternatively activated M2 macrophages improve autologous Fat Graft survival in a mouse model through induction of angiogenesis. Plast. Reconstr. Surg. 135, 140-149. doi: 10.1097/prs.0000000000000793

Place, E. S., George, J. H., Williams, C. K., and Stevens, M. M. (2009). Synthetic polymer scaffolds for tissue engineering. Chem. Soc. Rev. 38, 1139-1151. doi: 10.1039/B811392K

Poon, C. J., Pereira Cotta, M. V., Sinha, S., Palmer, J. A., Woods, A. A., and Morrison, W. A. (2013). Preparation of an adipogenic hydrogel from subcutaneous adipose tissue. Acta Biomater. 9, 5609-5620. doi: 10.1016/j.actbio. 2012.11.003

Rocco, N., Gloria, A., De Santis, R., Catanuto, G., Nava, M. B., and Accurso, A. (2016). Improving outcomes in breast reconstruction: from implant-based 
techniques towards tissue regeneration. Proc. CIRP 49(Suppl. C), 183-187. doi: 10.1016/j.procir.2015.11.012

Roehm, K. D., Hornberger, J., and Madihally, S. V. (2016). In vitro characterization of acelluar porcine adipose tissue matrix for use as a tissue regenerative scaffold. J. Biomed. Mater. Res. A 104, 3127-3136. doi: 10.1002/jbm.a.35844

Rubin, J. P., Bennett, J. M., Doctor, J. S., Tebbets, B. M., and Marra, K. G. (2007). Collagenous microbeads as a scaffold for tissue engineering with adiposederived stem cells. Plast. Reconstr. Surg. 120, 414-424. doi: 10.1097/01.prs. 0000267699.99369.a8

Rubin, J. P., DeFail, A., Rajendran, N., and Marra, K. G. (2009). Encapsulation of adipogenic factors to promote differentiation of adipose-derived stem cells. J. Drug Target. 17, 207-215. doi: 10.1080/10611860802669231

Sano, H., Orbay, H., Terashi, H., Hyakusoku, H., and Ogawa, R. (2014). Acellular adipose matrix as a natural scaffold for tissue engineering. J. Plast. Reconstr. Aesthet. Surg. 67, 99-106. doi: 10.1016/j.bjps.2013.08.006

Schmauss, D., Machens, H. G., and Harder, Y. (2016). Breast reconstruction after mastectomy. Front. Surg. 2:71. doi: 10.3389/fsurg.2015.00071

Sharma, A., Bhat, S., Nayak, V., and Kumar, A. (2015). Efficacy of supermacroporous poly(ethylene glycol)-gelatin cryogel matrix for soft tissue engineering applications. Mater. Sci. Eng. C Mater. Biol. Appl. 47, 298-312. doi: 10.1016/j.msec.2014.11.031

Simonacci, F., Bertozzi, N., Grieco, M. P., Grignaffini, E., and Raposio, E. (2016). Autologous fat transplantation for breast reconstruction: a literature review. Ann. Med. Surg. 12, 94-100. doi: 10.1016/j.amsu.2016.11.012

Stillaert, F. B., Di Bartolo, C., Hunt, J. A., Rhodes, N. P., Tognana, E., Monstrey, S., et al. (2008). Human clinical experience with adipose precursor cells seeded on hyaluronic acid-based spongy scaffolds. Biomaterials 29, 3953-3959. doi: 10.1016/j.biomaterials.2008.06.005

Sun, J., Xiao, C., Tan, H., and Hu, X. (2013). Covalently crosslinked hyaluronic acid-chitosan hydrogel containing dexamethasone as an injectable scaffold for soft tissue engineering. J. Appl. Polym. Sci. 129, 682-688. doi: 10.1002/app.38779

Tabit, C. J., Slack, G. C., Fan, K., Wan, D. C., and Bradley, J. P. (2012). Fat grafting versus adipose-derived stem cell therapy: distinguishing indications, techniques, and outcomes. Aesthetic Plast. Surg. 36, 704-713. doi: 10.1007/ s00266-011-9835-4

Tachi, M., and Yamada, A. (2005). Choice of flaps for breast reconstruction. Int. J. Clin. Oncol. 10, 289-297. doi: 10.1007/s10147-005-0527-4

Tan, H., Ramirez, C. M., Miljkovic, N., Li, H., Rubin, J., and Marra, K. G. (2009). Thermosensitive injectable hyaluronic acid hydrogel for adipose tissue engineering. Biomaterials 30, 6844-6853. doi: 10.1016/j.biomaterials. 2009.08.058

Tan, H. J., Rubin, P., and Marra, K. G. (2010). Injectable in situ forming biodegradable chitosan-hyaluronic acid based hydrogels for adipose tissue regeneration. Organogenesis 6, 173-180. doi: 10.4161/org.6.3.12037

Teti, A. (1992). Regulation of cellular functions by extracellular matrix. J. Am. Soc. Nephrol. 10(Suppl.), S83-S87.

Topcu, A., Aydin, O. E., Ünlü, M., Barutcu, A., and Atabey, A. (2012). Increasing the viability of fat grafts by vascular endothelial growth factor. Arch. Facial Plast. Surg. 14, 270-276. doi: 10.1001/archfacial.2011.1633

Uriel, S., Huang, J. J., Moya, M. L., Francis, M. E., Wang, R., and Chang, S.-Y. (2008). The role of adipose protein derived hydrogels in adipogenesis. Biomaterials 29, 3712-3719. doi: 10.1016/j.biomaterials.2008. 05.028

Vashi, A. V., Abberton, K. M., Thomas, G. P., Morrison, W. A., O'Connor, A. J., and Cooper-White, J. J. (2006). Adipose tissue engineering based on the controlled release of fibroblast growth factor-2 in a collagen matrix. Tissue Eng. 12, 3035-3043. doi: 10.1089/ten.2006.12. 3035

von Heimburg, D., Zachariah, S., Heschel, I., Kuhling, H., Schoof, H., Hafemann, B., et al. (2001). Human preadipocytes seeded on freeze-dried collagen scaffolds investigated in vitro and in vivo. Biomaterials 22, 429-438. doi: 10.1016/s0142-9612(00)00186-1

Wang, L., Johnson, J. A., Zhang, Q., and Beahm, E. K. (2013). Combining decellularized human adipose tissue extracellular matrix and adipose-derived stem cells for adipose tissue engineering. Acta Biomater. 9, 8921-8931. doi: 10.1016/j.actbio.2013.06.035

Wang, W., Cao, B., Cui, L., Cai, J., and Yin, J. (2013a). Adipose tissue engineering with human adipose tissue-derived adult stem cells and a novel porous scaffold. J. Biomed. Mater. Res. B Appl. Biomater. 101, 68-75. doi: 10.1002/jbm.b.32816

Wang, W., Cao, B., Cui, L., Cai, J., and Yin, J. (2013b). Adipose tissue engineering with human adipose tissue-derived adult stem cells and a novel porous scaffold. J. Biomed. Mater. Res. Part B 101B, 68-75. doi: 10.1002/jbm.b.32816

Widberg, C. H., Newell, F. S., Bachmann, A. W., Ramnoruth, S. N., Spelta, M. C., Whitehead, J. P., et al. (2009). Fibroblast growth factor receptor 1 is a key regulator of early adipogenic events in human preadipocytes. Am. J. Physiol. Endocrinol. Metab. 296:E121. doi: 10.1152/ajpendo.90602.2008

Yazawa, M., Mori, T., Nakayama, Y., and Kishi, K. (2015). Basic study of soft tissue augmentation by adipose-inductive biomaterial. J. Biomed. Mater. Res. B Appl. Biomater. 103, 92-96. doi: 10.1002/jbm.b.33180

Young, D. A., Ibrahim, D. O., Hu, D., and Christman, K. L. (2011). Injectable hydrogel scaffold from decellularized human lipoaspirate. Acta Biomater. 7, 1040-1049. doi: 10.1016/j.actbio.2010.09.035

Zhang, S., Lu, Q., Cao, T., and Toh, W. S. (2016). Adipose tissue and extracellular matrix development by injectable decellularized adipose matrix loaded with basic fibroblast growth factor. Plast. Reconstr. Surg. 137, 1171-1180. doi: 10. 1097/prs.0000000000002019

Zhu, M., Zhou, Z., Chen, Y., Schreiber, R., Ransom, J. T., and Fraser, J. K. (2010). Supplementation of fat grafts with adipose-derived regenerative cells improves long-term graft retention. Ann. Plast. Surg. 64, 222-228. doi: 10.1097/SAP. 0b013e31819ae05c

Conflict of Interest Statement: The authors declare that the research was conducted in the absence of any commercial or financial relationships that could be construed as a potential conflict of interest.

Copyright (c) 2018 Mahoney, Imbarlina, Yates and Marra. This is an open-access article distributed under the terms of the Creative Commons Attribution License (CC BY). The use, distribution or reproduction in other forums is permitted, provided the original author(s) and the copyright owner are credited and that the original publication in this journal is cited, in accordance with accepted academic practice. No use, distribution or reproduction is permitted which does not comply with these terms. 